medRxiv preprint doi: https://doi.org/10.1101/2022.02.13.22270914; this version posted February 17, 2022. The copyright holder for this preprint

(which was not certified by peer review) is the author/funder, who has granted medRxiv a license to display the preprint in perpetuity.

It is made available under a CC-BY 4.0 International license.

Confidential Pre-Publication Peer Review Manuscript

ORIGINAL RESEARCH

\section{Gaining Control of Combination Cancer Treatment Risk by Incorporating Cost and Value Data into the Drug Selection Process at the Point-of-Care}

A Science - Based Method to Drive Value for Patients, Providers, Health Systems and Payers Available online in \& PDF Adobe format here

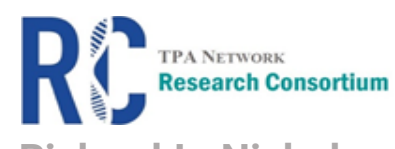

Richard L. Nicholas

\title{
Abstract
}

The use of combination drug therapies (e.g., immunotherapies, chemotherapies and drugs having distinct mechanisms of action) for the treatment of cancer is now widespread; as well, the repositioning of FDAapproved treatments for off-label indications. While much is known about their clinical effectiveness, there exists no study of the relative cost of novel multi-drug combinations vs. monotherapies or examinations as to how knowledge about comparative therapy costs may be leveraged by doctors, health systems and payers to identify therapies that are likely to be more effective, less wasteful and a financial value. We found that

1) combination multi-drug cancer regimens are often far less expensive than traditional monotherapies,

2) novel, multi-drug combinations are often better financial values than traditional monotherapies, and

3) having treatment cost and value data, at the point of care, enables the prompt selection of more costeffective medications and the avoidance of expensive low-value therapies that are financially wasteful.

We conclude that the effectiveness of value-based purchasing models may be amplified if providers and payers use comparative treatment cost data to augment and enhance their drug-selection decision making.

KEYWORDS: combination therapy, specialty pharmacy, precision medicine, value-based healthcare, healthcare AI, NGS, low clinical value drug, cancer

\section{Study Highlights}

What Is The Current Knowledge On The Topic?

We know that the effectiveness of targeted multi-drug combination therapies in the treatment of cancer is long established, ${ }^{1-4}$ that few clinicians are aware of the cost of the medications they prescribe, or which are more cost-effective, deliver a better return-on-investment or represent a financial value, ${ }^{8}$ and that it is intuitive to infer that a combination of multiple high-cost medications is far more costly than a monotherapy.

What Question Did This Study Address?

Although studies on the clinical impact of multi-drug cancer treatments abound, ${ }^{1-4}$ there are no examinations of the relative cost or value of combination therapies vs. that of traditional monotherapies, or how knowledge of how this data can be used in practice. A systematic method to calculate, evaluate and compare the relative cost of 1-, 2- and 3-drug combination cancer therapies is presented that can be used by providers, health systems and payers to better manage their oncology special pharmacy spend and drive better outcomes.

What Does This Study Add To Our Knowledge?

We show that multi-drug cancer therapies are not necessarily more costly than monotherapies; and that furnishing providers and payers with comparative treatment cost and value data to augment their complex medication selection decision making enables them to identify drugs that are a value, avoid those that are wasteful and create better targeted novel combination cancer therapies that represent a genuine value.

How Might This Change Combination Therapy Drug Selection Or Value-Based Oncology Management ? Clinicians have the tools, information and data with which to confidently develop novel drug combinations that customize molecular targeting, reduce waste and lower treatment costs. Payers now have a framework within which to drive value-based purchasing to gain control of their oncology specialty drug risk. Cancer patients will benefit from more personalized, efficient and effective therapies and less financial toxicity. 
medRxiv preprint doi: https://doi.org/10.1101/2022.02.13.22270914; this version posted February 17, 2022. The copyright holder for this preprint (which was not certified by peer review) is the author/funder, who has granted medRxiv a license to display the preprint in perpetuity.

\section{Background}

It is made available under a CC-BY 4.0 International license.

This study provides a methodology by which to measure and compare the cost and value of mono- and multidrug cancer treatment options; and demonstrates how having this data at the point-of-care can impact patient, physician and payer decision-making and better identify treatments that are a value, and ones that are wasteful.

\section{Method}

For this study, the combination drug therapy data used was furnished by CureMatch, Inc. Its Al-based therapeutic decision support platform identifies drugs known to act against specific cancer mutations then scores and ranks drug combinations that best target a tumor's actionable variants. ${ }^{5-7}$ Note that a cost analysis / value assessment can be performed with clinical data from an alternative drug combination / mutation-matching (scoring) source.

Focusing on 5 real-world case studies, we calculated the 3-month drug cost of each 1-, 2- and 3-drug combination treatment that was scored and ranked; and created an index by which to measure and compare their value.

- 45 combination therapies involving 22 unique drugs were priced; 19 drugs (86\%) are patent-protected brands and 2 are standard generic chemotherapies, 1 is a modestly-discounted brand-transitioning-to-generic drug .

- Of the recommendations, some 38 (84\%) employed 1 or more off-label drugs, creating a novel combination.

- Dosing is often reduced by $50 \%$ to $67 \%$ when used in for cancer drug combinations. We assessed each drug to see if size, package, dose or strength options enable this: 21 (95\%) of the 22 drugs offer such variety. To be cautious, we increased the price basis by $20 \%$ (from $33 \%$ to $40 \%$ and $50 \%$ to $60 \%$ ) for 2 - and 3 -drug treatments respectively, to compensate for any inefficiency owing to dose size, packaging or strength. For more about this assessment, and dosing practice methods, see Appendix A: Evolving Drug Dosing Constructs.

- Drug pricing is complex (see Appendix B. Pharmaceutical Pricing) and based here on AWP -15\% for the most cost-efficient drug package per Alchemy Health Care Solutions, a CMS-recognized pricing source (Feb 2022).

- Pricing reflects the full monotherapy dose for the indication which the drug is most commonly prescribed.

- When relevant, the following patient-specific physical attributes were used: Weight (180 lbs.) Height ( $\left.5^{\prime} 10^{\prime \prime}\right)$, Body Mass Index (25 lbs./in²) Body Surface Area (1.8 $\mathrm{M}^{2}$ ) and Glomerular Filtration Rate (125 mL/min).

\begin{tabular}{|c|c|c|c|c|c|}
\hline \multicolumn{3}{|c|}{ Rx Name and Type } & \multicolumn{3}{|c|}{ Strength, Size \& Packaging } \\
\hline $\begin{array}{l}\text { Generic } \\
\text { Name }\end{array}$ & $\begin{array}{l}\text { Brand } \\
\text { Name }\end{array}$ & $\frac{0}{\frac{0}{d}}$ & 旁 & $\begin{array}{l}\text { Available } \\
\text { Strengths } \\
\text { (Mgs) }\end{array}$ & $\begin{array}{l}\text { Units } \\
\text { per Pkg }\end{array}$ \\
\hline Abemaciclib & Verzenio & No & 0 & $50 / 100 / 150 / 200$ & 14 \\
\hline Apalutamide & Erleada & No & 0 & 60 & 120 \\
\hline Atezolizumab & Tecentriq & No & IV & $840 / 1200$ & $14 / 20$ \\
\hline Bevacizumab & Avastin & No & IV & 100 & $4 / 16$ \\
\hline Carboplatin & Paraplatin & Yes & IV & $50 / 150 / 450 / 600$ & $5 / 15 / 45 / 60 / 100$ \\
\hline Cisplatin & Platinol & Yes & IV & 1 & 100 \\
\hline Erdafitinib & Balversa & No & 0 & $3 / 4 / 5$ & $28 / 56 / 84$ \\
\hline Everolimus & Afinitor & Yes & 0 & $.25 / .50 .75 / 1.00$ & 28 \\
\hline Ivosidenib & Tibsovo & No & 0 & 250 & 60 \\
\hline Lenvatinib & Lenvima & No & 0 & 4/10 Mix & $5 / 10 / 15 / 60 / 90$ \\
\hline Leuprolide & Lupron Depot & No & SI & $7.5 / 22.5 / 30 / 45$ & 1 \\
\hline Niraparib & Zejula & No & 0 & 100 & 30 \\
\hline Olaparib & Lynparza & No & 0 & $100 / 150$ & $60 / 120$ \\
\hline Palbociclib & Ibrance & No & 0 & $75 / 100 / 125$ & 21 \\
\hline Pembrolizumab & Keytruda & No & IV & 100 & 2 \\
\hline Pemetrexed & Alimta & No & IV & $100 / 500$ & 1 \\
\hline Regorafenib & Stivarga & No & 0 & 40 & $21 / 28$ \\
\hline Ribociclib & Kisqali & No & 0 & 200 & $21 / 42 / 63$ \\
\hline Rucaparib & Rubraca & No & 0 & $200 / 250 / 300$ & 60 \\
\hline Sorafenib & Nexavar & No & 0 & 200 & 120 \\
\hline Talazoparib & Talzenna & No & 0 & $.25 / .50 .75 / 1.00$ & 30 \\
\hline Temsirolimus & Torisel & No & IV & 30 & 1 \\
\hline
\end{tabular}

\begin{tabular}{|c|c|c|c|}
\hline \multicolumn{4}{|c|}{ Dosing } \\
\hline 志怘 & $\begin{array}{l}\text { Days } \\
\text { per } \\
\text { Cycle }\end{array}$ & $\begin{array}{l}\text { Cycles } \\
\text { per } \\
\text { Month }\end{array}$ & $\begin{array}{l}\text { Units } \\
\text { per } \\
\text { Month }\end{array}$ \\
\hline $24.8 \mathrm{H}$ & 28 & 1.00 & 56 \\
\hline $3.0 \mathrm{D}$ & 28 & 1.00 & 120 \\
\hline $27.0 \mathrm{D}$ & 21 & 1.33 & 20 \\
\hline $20.0 \mathrm{D}$ & 21 & 1.33 & 52 \\
\hline $5.0 \mathrm{D}$ & 28 & 1.00 & 60 \\
\hline $36.0 \mathrm{D}$ & 21 & 1.33 & 500 \\
\hline $59.0 \mathrm{H}$ & 28 & 1.00 & 56 \\
\hline $30.0 \mathrm{H}$ & 28 & 1.00 & 28 \\
\hline $93.0 \mathrm{H}$ & 28 & 1.00 & 60 \\
\hline $28.0 \mathrm{H}$ & 28 & 1.00 & 60 \\
\hline $3.0 \mathrm{H}$ & 28 & 1.00 & 7.5 \\
\hline $36.0 \mathrm{H}$ & 28 & 1.00 & 90 \\
\hline $11.9 \mathrm{H}$ & 28 & 1.00 & 60 \\
\hline $29.0 \mathrm{H}$ & 28 & 1.00 & 21 \\
\hline $22.0 \mathrm{D}$ & 21 & 1.33 & 8 \\
\hline $3.5 \mathrm{H}$ & 21 & 1.33 & 5 \\
\hline $28.0 \mathrm{H}$ & 21 & 1.00 & 84 \\
\hline $32.0 \mathrm{H}$ & 21 & 1.00 & 63 \\
\hline $17.0 \mathrm{H}$ & 28 & 1.00 & 60 \\
\hline $25.0 \mathrm{H}$ & 28 & 1.00 & 120 \\
\hline $90.0 \mathrm{H}$ & 28 & 1.00 & 30 \\
\hline $31.0 \mathrm{H}$ & 28 & 1.00 & 4 \\
\hline
\end{tabular}

\begin{tabular}{|c|c|c|}
\hline $\begin{array}{l}\text { Init Cost } \\
\text { WP-15\% }\end{array}$ & \multicolumn{2}{|c|}{$\begin{array}{l}\text { Cost per } \\
\text { Month at } \\
\text { AWP }-15 \%\end{array}$} \\
\hline 237.85 & s & 13,319 \\
\hline 109.08 & s & 13,090 \\
\hline 502,28 & s & 13,361 \\
\hline 203.22 & S & 14,055 \\
\hline 1.20 & S & 72 \\
\hline 0.31 & S & 203 \\
\hline 402.14 & S & 22,520 \\
\hline 514.73 & S & 14,412 \\
\hline 511.41 & S & 30,685 \\
\hline 346.17 & S & 20,770 \\
\hline 460.73 & s & 3,455 \\
\hline 259.14 & s & 23,323 \\
\hline 126.50 & s & 7,590 \\
\hline 678.73 & s & 14,253 \\
\hline $1,309.26$ & s & 13,931 \\
\hline 808.61 & S & 5,377 \\
\hline 238.80 & S & 20,059 \\
\hline 245.49 & S & 15,466 \\
\hline 147.65 & s & 8,859 \\
\hline 188.64 & S & 22,637 \\
\hline 551.88 & s & 16,556 \\
\hline 1.203 .60 & & 4,814 \\
\hline
\end{tabular}

These price indicators are used below in an index that enables the evaluation and comparison of the cost and value of each treatment option (i.e., tumor mutation matching score / dollar). Note that the prices indicated are for drugs only and do not include any expense for NGS testing, drug administration, professional services, etc. 
medRxiv preprint doi: https://doi.org/10.1101/2022.02.13.22270914; this version posted February 17,2022 . The copyright holder for this preprint (which was not certified by peer review) is the author/funder, who has granted medRxiv a license to display the preprint in perpetuity.

It is made available under a CC-BY 4.0 International license.

The following information is intended to be of assistance in understanding and interpreting the exhibits below:

- There are more than 300 FDA-approved drugs that are used in the US in the treatment of cancer.

- There are approximately 4.5 million possible 1-, 2- and 3-drug combinations of these medications.

- A Pathogenic Marker is a genetic alteration known to cause and/or be associated with cancer.

- An Actionable Marker is a genetic alteration that has a known response to an existing FDA-approved therapy.

- Combinations Considered is the number of 1,2 , or 3 drugs combinations that were subject to analysis.

- Relevant Combinations is the total number of drugs that were found to be relevant to the patient based on their tumor's unique molecular profile, and that were considered in the analysis.

- Drugs are selected based on their potential to target tumor mutations. Treatment Score reflects the targeting effectiveness of one combination against all pathogenic alterations. Represented as a percentage, it may be used to compare regimens within the same profile or between different cases or reports.

- The three highest scoring combination treatments are presented for 1-, 2- and 3-drug regimens.

- Drugs in italics are FDA-approved, but repositioned (i.e., used off-label) for the specific indication.

- The Full Rx Cost / Month figure is the sum of the full cost of all the drugs used, at full dosage, for one month.

- The Treatment Cost at Adjusted Dose is the 3-month cost of treatment, after appropriate dose reductions.

- We define best value as the lowest treatment cost relative to the drug combination/mutation matching score. The Value: \$ / CM Point is essentially a comparative value metric of predicted targeting effectiveness.

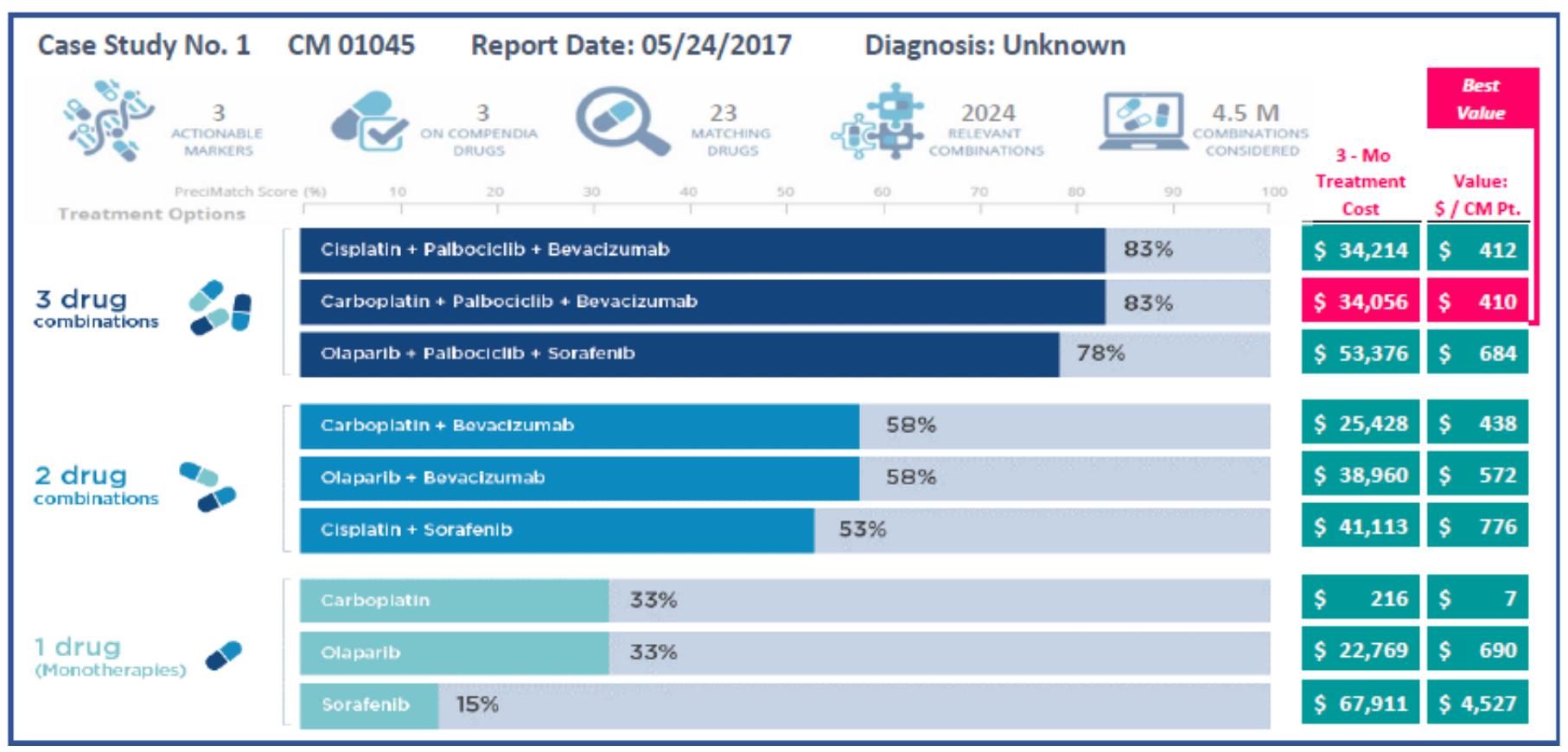

Clinically, the case above should be interpreted as follows: 3 pathogenic markers were identified, all actionable; and 23 drugs were molecularly matched to an actionable marker (all but 3 of which would be used off-label). Some 2,024 relevant multi-drug combinations were identified, evaluated, scored and ranked. The top ranked combinations of each type are shown: the top-scoring 3-drug options are all promising with scores of $83 \%$.

Note: It is counterintuitive that a combination of 3 high-cost drugs could cost less than 1-and 2-drug options. Only by having price data is it possible to identify the 3-drug Carboplatin/Palbociclib/Bevacizumab combination (with an index of $\$ 410$ or $\$ 34,056 \div 83$ ) as the best value versus the other treatment options.

Essentially, it is this utility - the ability to measure and compare value when selecting high-cost specialty cancer therapies - that is the subject of this study. Below are the results of the case studies we examined. 
medRxiv preprint doi: https://doi.org/10.1101/2022.02.13.22270914; this version posted February 17,2022 . The copyright holder for this preprint (which was not certified by peer review) is the author/funder, who has granted medRxiv a license to display the preprint in perpetuity.

It is made available under a CC-BY 4.0 International license .

\section{Results}

We found that when multiple cancer drugs are prescribed concurrently, and the dosage of each component drug is adjusted appropriately, multi-drug combination regimens are often less costly than traditional monotherapies, and often represent better financial values versus many (wasteful, costly) single-drug therapies. We found that

- 3 of the 5 best values were 3-drug therapies, and two were 2-drug combination regimens;

- many costly, yet popular, monotherapies were found to be of low-clinical-value, and therefore wasteful; and

- although not shown, when clinician-selected drug regimens are scored they rarely score above $20 \%$.

Case Studies 1 and 2: the selection of either popular drug Olaparib or Sorafenib would be a poor choice, given the other top-ranked combination treatment options, each a far better value (for this specific tumor profile).

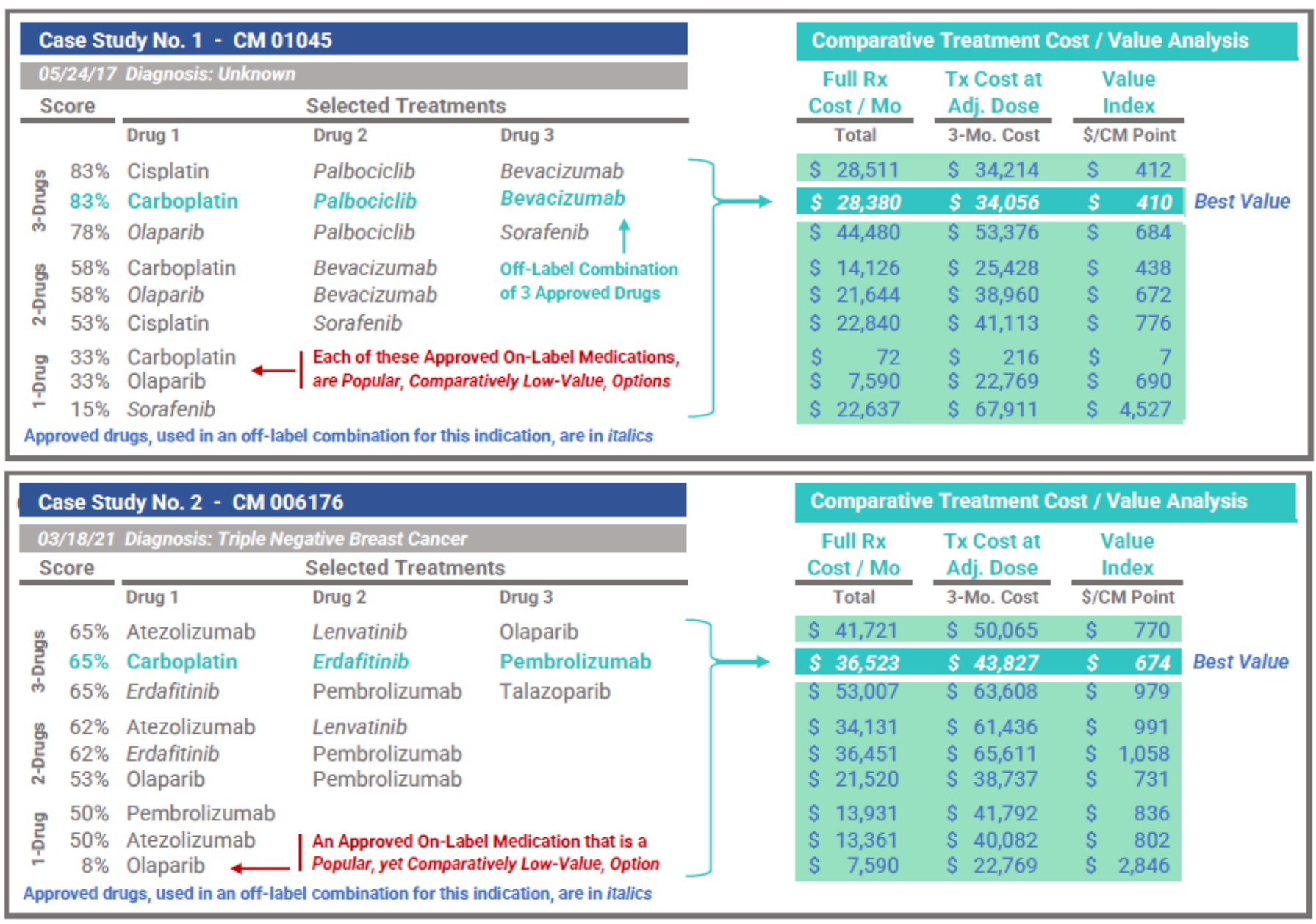

Case Study 3: The 6 top-ranked therapies scored 82 - 84\%; the best value is the least costly (by a large margin).

\begin{tabular}{|c|c|c|c|c|c|c|c|c|c|}
\hline \multicolumn{5}{|c|}{ Case Study No. 3 - CM 006178} & \multicolumn{5}{|c|}{ Comparative Treatment Cost / Value Analysis } \\
\hline \multicolumn{5}{|c|}{ 03/18/21 Diagnosis: Prostate Adenocarcinoma } & \multirow{2}{*}{$\begin{array}{l}\text { Full Rx } \\
\text { Cost / Mo }\end{array}$} & \multirow{2}{*}{$\begin{array}{l}\text { Tx Cost at } \\
\text { Adj. Dose }\end{array}$} & \multirow{2}{*}{\multicolumn{2}{|c|}{$\begin{array}{l}\text { Value } \\
\text { Index }\end{array}$}} & \\
\hline & ore & & Selected Treatme & & & & & & \\
\hline \multirow{4}{*}{ 号 } & & Drug 1 & Drug 2 & Drug 3 & Total & 3-Mo. Cost & & M Point & \\
\hline & $84 \%$ & Apalutamide & Olaparib & Pembrolizumab & S 34,610 & \$ 41,532 & \$ & 494 & \\
\hline & $84 \%$ & Lenvatinib & Leuprolide & Pembrolizumab & S 38,156 & S 45,788 & s & 545 & \\
\hline & $84 \%$ & Lenvatinib & Pembrolizumab & Rucaparib & S 43,560 & S 52,271 & S & 622 & \\
\hline & $82 \%$ & Apalutamide & \multirow{3}{*}{\multicolumn{2}{|c|}{$\begin{array}{l}\text { Pembrolizumab } \\
\text { Pembrolizumab } \\
\text { Pembrolizumab }\end{array}$}} & \$ 27,020 & S 48,636 & s & 593 & \\
\hline & $82 \%$ & Olaparib & & & $S 21,520$ & S 38,737 & $s$ & 472 & Best Value \\
\hline & $82 \%$ & Lenvatinib & & & S 34,701 & S 62,461 & S & 762 & \\
\hline & $79 \%$ & Pembrolizumab & \multirow{3}{*}{\multicolumn{2}{|c|}{$\begin{array}{l}2 \text { Approved On-Label Monotherapies } \\
\text { that produced Very Different Scores }\end{array}$}} & S 13,931 & S 41,792 & s & 529 & \\
\hline & $17 \%$ & Leuprolide & & & S $\quad 3,455$ & S 10,366 & S & 610 & \\
\hline & $17 \%$ & Lenvatinib & & & S 20,770 & S 62,311 & s & 3,665 & \\
\hline
\end{tabular}


medRxiv preprint doi: https://doi.org/10.1101/2022.02.13.22270914; this version posted February 17, 2022. The copyright holder for this preprint (which was not certified by peer review) is the author/funder, who has granted medRxiv a license to display the preprint in perpetuity.

It is made available under a CC-BY 4.0 International license .

Case Study 4: A 2-drug combination represents the best value, achieving a comparatively high score of $74 \%$, while creating a significant financial savings versus all of the top-scoring 3-drug recommendations.

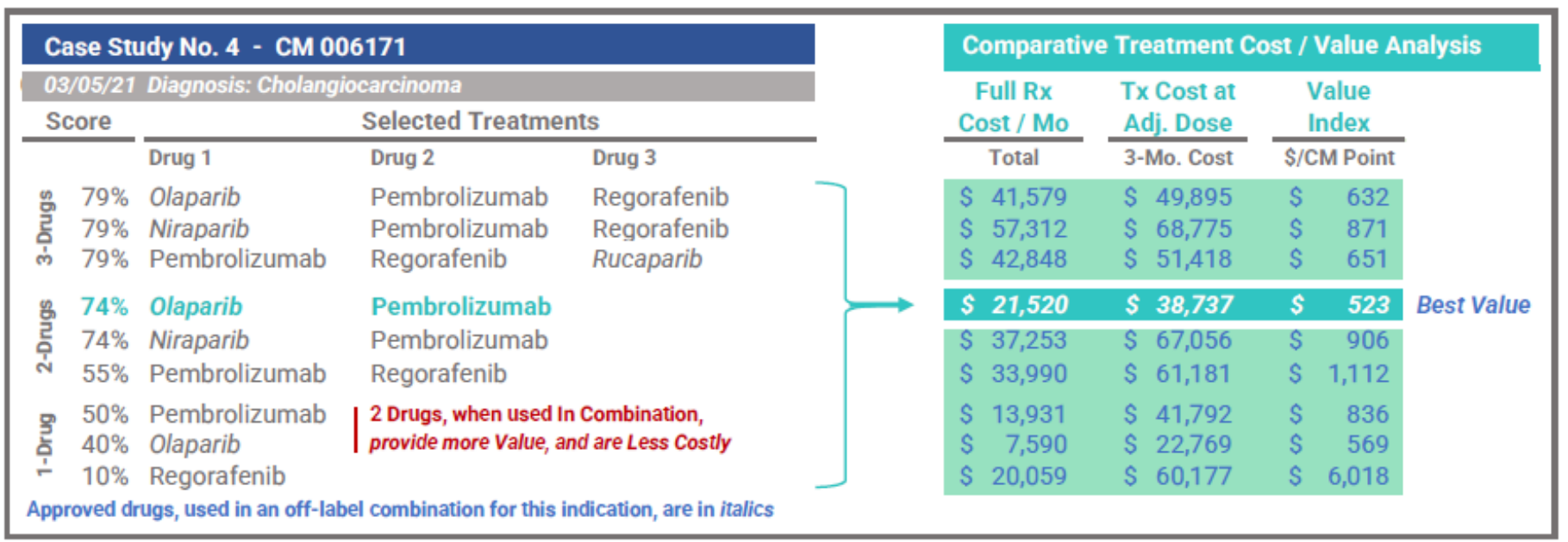

Case Study 5: The cost of Ivosidenib/Palbociclib/Temsirolimus combined is less than Ivosidenib alone.

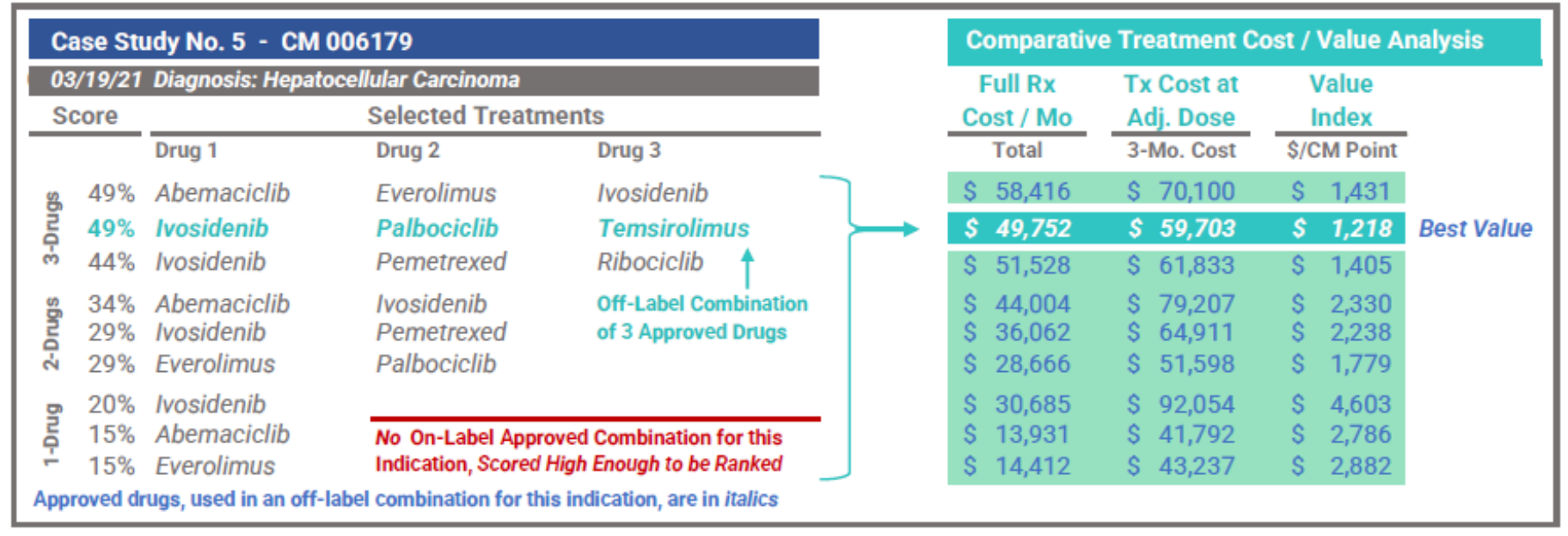

\section{Discussion}

Advanced precision cancer drug treatment generates thousands of possible drug combinations for a clinician to identify, evaluate and consider; a task that is beyond human cognitive capability without Al-enabled assistance. Beyond the enormous clinical value of such technology, our research evidences that when supplemented with comparative treatment cost data, clinicians are able to identify multi-drug cancer therapies that are better, less costly and genuine financial values vs. more popular low-clinical-value monotherapy options.

We found that each of the five combination treatments deemed to be best values were actually 2- and 3-drug combinations of singularly very costly drugs; something that is not intuitive without drug cost data. In that most cancer treatments are not effective, equipping providers with point-of-care price data is essential to driving value.

\section{Conclusions}

Few oncologists are aware of the cost, effectiveness or value of the treatments they prescribe. ${ }^{8}$ This often results in hugely expensive, yet ineffective, treatment. At the same time, using DNA sequencing and Al-based systems to create customized molecular tumor matching treatment options is becoming the standard of cancer care. ${ }^{5-7}$ This creates a clear and imminent opportunity to replace waste with value in combination cancer care.

Oncologists need and deserve relative clinical and cost data, at the point of care, to help them avoid wasteful treatments and to identify ones that are a genuine financial value. Payers can use these new technologies to guide care, control utilization and better manage their finite resources by expanding their organization's valuepurchasing to include specialty cancer drugs. Uninformed, high-consequence oncology prescribing is not consistent with value-based care. This study provides evidence that there is no longer a reason for it to continue. 
medRxiv preprint doi: https://doi.org/10.1101/2022.02.13.22270914; this version posted February 17, 2022. The copyright holder for this preprint (which was not certified by peer review) is the author/funder, who has granted medRxiv a license to display the preprint in perpetuity.

\section{Key Terms and Concepts}

It is made available under a CC-BY 4.0 International license .

This section is intended to provide the reader with an understanding of, and context for, some of the important terms, concepts and constructs discussed herein that may not be common knowledge to laypersons.

- Targeted Cancer Therapy

Targeted cancer therapies, aka molecularly targeted drugs, are deliberately chosen precision medicines and agents that interfere with specific molecular targets that are involved in the growth, progression and spread of cancer. They do this by leveraging data / information about a tumor's unique genomic profile, in contrast with chemotherapy that acts rather indiscriminately on all rapidly-dividing normal and cancerous cells.

- Combination Drug Therapy

Combination drug therapy is a treatment modality that combines 2 or more therapeutic agents to enhance efficacy (versus a single-drug approach) by targeting key pathways in a synergistic or additive way or by providing multiple opportunities for a response to an agent. First employed in 1965 to successfully reduce tumor burden and prolong remission in leukemia patients, combination therapies have been used to treat many diseases, most notably HIV/AIDS, since 1996 when the FDA-approved the drug cocktail became the new standard of care for HIV. FDA-approved multi-drug therapies to treat cancer date back to the 1990's.

Multi-drug cancer treatments have proven to be so successful that drug makers are now researching, and marketing, pre-packaged multi-drug therapies. A well-known example is OPDIVO ${ }^{\circledR}+$ YERVOY $^{\circledR}$, an FDAapproved 2-drug immunotherapy combination used to treat some mesotheliomas. Each drug helps active $T$ cells provide protection from foreign threats in different yet complementary ways. OPDIVO ${ }^{\circledR}$ (nivolumab) helps active $T$ cells identify cancer cells that are hiding; YERVOY ${ }^{\circledR}$ (ipilimumab) helps generate more active $T$ cells to seek and destroy more cancer cells. The safety, efficacy and cost-effectiveness of combination multi-drug therapy is well documented ${ }^{1-4}$ and, as such, they have become a cornerstone of cancer treatment.

- Drug Repositioning / Off-Label Use

Drug repositioning, aka off-label drug use, is a therapeutic approach whereby current pharmaceutical agents primarily used to treat one disease are used to treat a different disease. A good example of drug repositioning is, Rapalog, an immunosuppressant that is primarily used after an organ transplant to prevent graft rejection, which has shown to have cancer prevention properties, owing to its mTOR inhibitory ability.

Apart from pre-packaged FDA-approved combination therapies that address specific gene mutations (e.g., those targeted by OPDIVO ${ }^{\circledR}+$ YERVOY $\left.^{\circledR}\right)$, off-label drug use is associated with the use of FDA-approved drugs in combinations intended to address gene mutations in novel ways; the premise being that there is a greater likelihood that a novel combination therapy will yield a better outcome the first time vs. repeated attempts using ordinary treatments (often at a lower overall long-term cost). While approved drug safety protocols and known pharmacokinetic profiles are evaluated and expertly addressed, some oncologists are slow adopters who reserve this practice only for late-stage patients, when standard monotherapies and prepackaged combinations have failed or when genomic markers indicate they may be effective.

- Effectiveness

The terms effective and ineffective are used herein to refer to the degree to which there exists a molecular rationale to prescribe the treatment; and not intended to describe the effectiveness of the therapy itself.

- Novel

The term novel is used herein to refer specifically to a combination of FDA-approved drugs, some of which may be repositioned or used off-label. It is not intended to infer that the therapy by itself is novel.

- Value-Based

The term value-based is used to describe healthcare payment, reimbursement and delivery frameworks aimed at improving quality and bettering outcomes for patients.; with provider payment and incentive models that reward quality improvement and health outcomes over volume; appreciating the reality that payer financial resources are finite. Therefore, value may be defined as health outcomes per unit of cost. 
medRxiv preprint doi: https://doi.org/10.1101/2022.02.13.22270914; this version posted February 17, 2022. The copyright holder for this preprint (which was not certified by peer review) is the author/funder, who has granted medRxiv a license to display the preprint in perpetuity.

\section{Limitations}

It is made available under a CC-BY 4.0 International license .

This analysis does not look to emulate the academic rigor that is synonymous with a scientific study that might also consider a wider scope of treatment costs, health outcomes data, long-term medical expenses, etc. Similarly, we did not focus on being overly precise as it relates to calculating combination drug therapy costs as our objective was only to fairly illustrate the relative cost difference between treatment options; understanding that the primary purpose of this analysis is to show that intuition-based treatment selection logic (e.g., multidrug therapies are more costly than monotherapies), and the limits of human cognitive ability, both warrant augmenting complex clinical decision making with Al-enabled support (and providing POC treatment cost data).

While these results are meaningful, more research is needed to fully examine the extent to which providing comparative point-of-care treatment cost data is able to reduce medication waste and drive value purchasing.

\section{Disclosures}

The Research Consortium serves as a healthcare industry advisor and payer product development consultant to CureMatch, Inc. which provided partial funding for this research. No funding source had any role in any aspect of this analysis and the existence of any relationship does not constitute a conflict of interest, or otherwise bias the impartiality, or compromise the integrity, of this study.

\section{Data Availability}

This analysis was prepared by the Research Consortium. For more information or data, please contact the author, Richard Nicholas, at Richard@ResearchConsortium.org or (858) 395 - 4114.

\section{Scientific References}

Below are several studies that provide clinical support for the science and technology discussed herein, including the landmark NIH-funded I-PREDICT study recognized by the American Society for Clinical Oncology as a major achievement in cancer research in 2017 and featured in Fmr. NIH Director Dr. Francis Collins' 04/19 blog.

1. Molecular profiling of advanced malignancies guides first-line $\mathrm{N}$-of- 1 treatments in the I-PREDICT treatment-naïve study Sicklick...Kurzrock, Genome Medicine (13) 1552021 https://DOI.org/10.1186/s13073-021-00969-w

2. Molecular profiling of cancer patients enables personalized combination therapy: the I-PREDICT study Sicklick, Nature Medicine (25) 744-750 2019 https://DOI.org/10.1038/s41591-019-0407-5

3. Real-world data from a molecular tumor board demonstrates improved outcomes with a precision N-of-One strategy patients Kato, Nature Communications (11) 49652020 https://DOl.org/10.1038/s41467-020-18613-3

4. The Crossroads of Precision Medicine and Therapeutic Decision Making Boichard....Kurzrock, Cancers, 2020 12(1) https://DOl.org/10.3390/cancers12010166

5. Precision Oncology: The UC San Diego Moores Cancer Center PREDICT Experience Schwaerderle...Kurzrock, Molecular Cancer Therapeutics, 2016 15(4):743-52. https://DOI: 10.1158/1535-7163.MCT-15-0795

6. Significance of scores generated by a cancer therapy matching engine for patient outcomes. Perlina, ASCO, 2021 https://DOI: 10.1200/JC0.2021.39.15_suppl.e15099

7. Comparison of 3 Commercial Decision Support Platforms for Matching of NGS Results with Therapies in Patients with Cancer Perakis, ESMO Open, 2020 https://DOI 10.1136/esmoopen-2020-000872

8. Physician awareness of drug cost: a systematic review Allan GM, Lexchin J, Wiebe N. PLoS Med. 2007 Sep;4 https://DOI: 10.1371/journal.pmed.0040283

9. Dosing de novo combinations of two targeted drugs: Towards a customized precision medicine approach to advanced cancers Liu...Kurzrock, Oncotarget 2016 Mar 8; 7(10): 11310-11320 https://DOI:10.18632/oncotarget.7023 


\section{Appendix A : Combination Drug Dosing Challenges}

As a point of distinction, dose refers to a specified amount of medication taken at one time and dosage and dosing refer to the specific amount, number and frequency of doses taken over a specified period of time.

The dose of a drug modulates whether patients will experience optimal effectiveness, toxicity or no effect at all. With respect cancer drug dosing, the goal is to maximize efficacy and minimize toxicity. Traditionally, dosages have been calculated based largely upon a patient's specific situation e.g., body surface area/mass (a factor of weight/height), age, gender, smoking, liver and kidney function, disease-specific considerations, possible drug/food interactions, etc. This approach is based on the theory that larger patients have a greater volume of distribution and higher metabolizing capacity, thereby requiring more of a drug to achieve the same effect.

Traditional dosing has been normalized to minimize interindividual variation. Correct dosing of cancer drugs is more complicated however as side effects are a key reason for patient nonadherence / early discontinuation. Moreover, dosing of combination cancer therapies can be challenging as it requires dose reductions in order to spare normal cells, while simultaneously creating the desired cytotoxic effect on the targeted cancer cells. This is especially true when two or more drugs of the same class are used, or when there are overlapping targets.

Informed, forward-thinking oncology practices are adopting personalizing (adjusted) dosing based on individual pharmacokinetics (i.e., the movement of drugs within the body); a practice that is consistent with the underlying premise of personalized/precision medicine which is to tailor treatment and care to the individual patient and their specific disease. It is not enough to select the right drug for a patient; it is critical that the dosage be correct.

In the treatment of cancer, combination drug therapy involves lowering the dose of 1 or more component drugs. While not universal, it is a common practice in 2-drug combinations to start with $~ 50 \%$ of the usual dose of each drug and for 3-drug combinations at 33\% of the usual dose noting that lower dosing often does not fare worse than higher dosing or alter efficacy. ${ }^{9}$ Many cancer drugs are formulated, sized, packaged and priced to enable a wide variety of precision dosing options and make it easier to develop an optimal personalized dosing regimen.

Beyond clinical considerations, given the exceedingly high cost of many cancer therapies (e.g. $\$ 30,000+/ \mathrm{mo}$.), drugs that are inappropriately dosed create significant, avoidable medical expense. Waste associated with nonoptimized drug therapy in the US is believed to be a half trillion dollars per year; $\approx 15 \%$ of our healthcare budget. Drug regimens must be more precisely tailored to each individual. Cancer - where nonadherence and early medication discontinuation pose real, significant and unnecessary financial burden - is no exception.

Counterintuitively, we evidence that the use of expensive cancer drugs does not need to result in an excessively high treatment cost. even in combination, when selected and dosed correctly. These high-cost medications may actually work to lower the total cost of care; thereby creating a genuine value. To accomplish this, combination drug treatments must be effective for every patient; i.e., they must be accurately dosed.

Many drug manufacturers recognized that certain of their products were formulated, sized, packaged and/or priced inefficiently (at least for the US market), such that it made precision dosing a challenge in practice. Most now offer a variety of dosing options; in part, to make their products attractive for combination and off-label use. There are several practices and techniques that may be employed to more precisely tailor a cancer patient's dosages to support novel multi-drug combination treatment and make these therapies able to benefit a wider patient population. These include pill and package splitting, dose cycle alteration, loading doses, fractionated dosing, dose rounding, split fill dispensing, treatment sequencing and scheduling adjustments, etc. Each is discussed in detail below in Appendix B: Evolving Drug Dosing Constructs.

\section{Therapeutic Index and Combination Drug Treatment}

Therapeutic index refers to the measure of the degree of fluctuation a drug is known to have over a dosing interval before it results in toxicity due to high peak concentrations. It is the ratio between the toxic dose and the dose at which the drug becomes effective. A drug having a low therapeutic index requires concentrations to be maintained within a narrow therapeutic range. This narrow therapeutic window typically limits the dose that can be achieved as a slight dosage variation may induce an adverse drug reaction or treatment failure. A drug having a high or wide therapeutic index is preferable to one having a low one as a patient would have to take a much higher dose of such a drug to reach the toxic threshold than that required to elicit the therapeutic effect. 
medRxiv preprint doi: https://doi.org/10.1101/2022.02.13.22270914; this version posted February 17, 2022. The copyright holder for this preprint (which was not certified by peer review) is the author/funder, who has granted medRxiv a license to display the preprint in perpetuity.

It is made available under a CC-BY 4.0 International license.

Most chemotherapies have a narrow therapeutic index. Unlike immunotherapies that require continuous dosing however, some cancer medications are dosed cyclically and can be adjusted based on clinical pharmacokinetic analysis performed on multiple blood samples drawn over a period of time. These wider therapeutic index drugs can often be given at intervals that exceed the drug's half-life without increasing toxicity.

By reducing the dose of the drugs used in a combination therapy - and leveraging the precise individualized dosing enabled by the specificity with which certain therapies deliver potent targeted cancer agents - the composite therapeutic index of the combination treatment may possibly be widened, thereby enhancing the therapy's utility and expanding its ability to provide clinical benefit to a much broader patient population.

\section{Evolving Drug Dosing Constructs}

In an ideal world, drugs would be available individually, in many different dose sizes and strengths and priced accordingly. As this is not the case, for clinicians and oncology pharmacists to achieve a desired reduced dose, challenges may need to be overcome. Here is how these challenges may be effectively addressed.

\section{- Package Sizing and Pack-Splitting}

While it is true that certain drug packaging can simultaneously drive-up costs and deter precision dosing, many medications are packaged to facilitate reduced dosing over time. By example, by combining different dose sizes in the same blister pack, Lenvima ${ }^{\circledR}$ (Lenvatinib) was originally packaged in 4- and 10-mg capsules to achieve a $24 \mathrm{mg}$ dose to treat thyroid cancer (with similar packaging for 20-, 14- and 10-mg daily dosages). After being approved for other indications, 18-, 12-, 8- and 4-mg dose options were created. As many blister packs contain doses of different strengths, pack-splitting can facilitate precise dosing and reduce waste. Beyond its clinical value, multiple dosing options create an opportunity for substantial payer/patient savings.

- Drug Half-Life and Dose Cycle Alternation

The half-life of a drug is an estimate of the time it takes for the drug's active substance in a patient's body to be reduced by half. Drugs having a shorter half-life tend to act quickly, although their effects may wear off rapidly, often resulting in the need to be taken several times a day. Drugs having a longer half-life may take longer to start working, although their effects may persist longer, resulting in a need to be dosed once a day, week, month or less frequently. A drug's half-life varies based on many drug- and patient-specific variables.

Given the half-life of many cancer agents, small differences in daily doses generally don't produce clinically meaningful results in the context of steady-state daily dosing. As such, minor drug regimen changes to reduce the dosage and mitigate waste are viable. Typically, this is done by taking one larger pill/capsule a day vs. 2 smaller ones; adjusting daily doses over a few days (e.g., 1 dose for 5 days and another for 3 days); extending dosing cycle intervals, etc. Most state laws accommodate practices to enable for patient-specific drug regimen tailoring. It also presents a real opportunity to achieve substantial payer and patient savings.

- Loading Dose

Loading dose refers to an initial high dose of a drug that has a long half-life that is given at the beginning of a course of a treatment to allow for dosing once, twice or three times daily as the large degree of fluctuation over the dosing interval does not result in toxicity due to high peak concentrations. When done, only a low maintenance dose is required to keep the amount of the drug in the body at the appropriate therapeutic level (otherwise, it would take longer to reach the appropriate amount of the drug in the body). Drugs that lend themselves to this practice have a wide therapeutic index, which enables dosing at intervals longer than the drug's half-life. In practice, this can result in more precise dosing, less medication waste and reduced cost.

\section{- Fractionated Dosing}

Many cancer drugs (having a wider therapeutic index) are dosed cyclically, making them candidates for adjustment based on regular clinical pharmacokinetic analysis; customizing the treatment by changing the dosing schedule. Fractionated dosing is the process of dividing one dose into multiple fractions to change dose intensity while reducing peak concentration, (to reduce toxicity and prolong exposure to the drug to ensure that a greater number of cancer cells are impacted). It has been shown to improve tolerability without impacting antitumor activity, thereby potentially widening the therapeutic window of many cancer agents. 
medRxiv preprint doi: https://doi.org/10.1101/2022.02.13.22270914; this version posted February 17, 2022. The copyright holder for this preprint (which was not certified by peer review) is the author/funder, who has granted medRxiv a license to display the preprint in perpetuity. It is made available under a CC-BY 4.0 International license.

- Pill Splitting

Pill splitting is the practice of cutting a pill in half to adjust a dose and/or to reduce costs (by up to 50\%) by purchasing higher-dose pills. It is a common insurer- and FDA-approved practice. Film-coated pills, capsules and extended-release tablets cannot be split; and many dosage forms cannot be crushed or compounded. While tablets that do not include pill-splitting information in the label have not been evaluated by the FDA to ensure that the resulting halves contain the same drug content or will work the same way as the entire pill, it is a misconception that only scored pills may be split. Depending upon the desired objective, exact equal doses may not be of clinical significance: splitting pills with a long half-life and wide therapeutic index typically poses little risk. Pill splitting should be doctor approved and is best done with a common pill-splitting device.

- Split-Fill Dispensing

Oral chemotherapies are often perceived to be safer and/or less toxic than their intravenously-delivered counterparts; a perception that is inaccurate. In fact, many patients stop taking oral medications long before the initial monthly treatment regimen is completed, or drug supply finished. Whether this is the result of intolerable side effects or unrealized therapeutic benefit matters little, considerable medication waste and enormous financial consequences ensue, especially when high-cost specialty cancer drugs are involved. Split-fill dispensing is when high-cost drugs having pronounced side effects can be tried for a short period to confirm tolerance and effectiveness before a full supply is dispensed. In practice, a 30-day script is reduced by half and 15-day supplies are provided twice monthly for a few months until the dosing target is achieved.

- Dose Rounding

Many drugs used to treat cancer (e.g., chemotherapies) are IV-administered using single-dose vials that are sized in ways that do not always align with commonly administered doses; often, they contain more drug than the patient needs while in other situations many vials are needed to create a full patient dose. Packaging high-cost drugs into single-size vials is very inefficient, both in clinical and financial terms, as the optimal dose typically varies based on a patient's individual characteristics (e.g. weight, body size). Partially full vials are of little clinical use as they are often in preservative-free formulations that must be used within 6 hours of opening. One-size vial packaging creates $\$ 1.5+$ billion in avoidable leftover drug waste annually.

Drug rounding refers to a technique aimed at lowering the cost of patient care by reducing medication waste and associated costs, without sacrificing efficacy or increasing toxicity. Typically, any calculated dose that falls within $5 \%$ to $10 \%$ of the established dose is rounded; the rationale being that rounding within this range will not have a negative impact on the safety or effectiveness of the therapy. In practice, dose-rounding options include rounding to the nearest vial size if the rounded dose falls within $10 \%$ of the prescribed dose, rounding down to the nearest vial size, and rounding to the nearest vial-size increment (e.g., 50-mg vial for a specific drug). Related methods include syringe increment rounding and rounding to a certain decimal place.

- Treatment Sequencing / Scheduling

The timing and sequence of a drug's administration are critical to a treatment's efficacy and safety. While many traditional cancer therapies are delivered on a strict schedule, the more widespread use of targeted agents employing varied mechanisms of action make it possible to consider different sequencing strategies.

Determining which drugs should be given, in what order or combination, is complicated. Scheduling variables (e.g., concurrent/sequential administration, sequencing order, therapy time, dose intervals, recovery period) can have a consequential effect on a therapy's efficacy. Due to a paucity of guidelines for optimal sequencing of cytotoxic or targeted agents, treatment sequencing has become a critical issue in oncology research and clinical practice, recognizing the importance of timing for optimizing drug utilization and therapeutic effect.

\section{Dose Reduction Assessment}

The formulation, size, packaging, strength, half-life, dose and price of each study drug was reviewed to determine if a reduced dose can be created when common dosing practices are employed. This is largely a factor of the number of a drug's forms, strengths and presentations; dosing frequency, etc. The variety of each drug's possible dosing options was measured and classified as High (H), Moderate (M) or Low (L), where M denotes more than adequate variety. Conservatively, 21 (95\%) of the 22 drugs were found to offer acceptable (M- or H-level) variety. 
medRxiv preprint doi: https://doi.org/10.1101/2022.02.13.22270914; this version posted February 17, 2022. The copyright holder for this preprint (which was not certified by peer review) is the author/funder, who has granted medRxiv a license to display the preprint in perpetuity. It is made available under a CC-BY 4.0 International license .

\section{Appendix B: Pharmaceutical Pricing}

Similar to most products, prescription drugs move through a supply chain to get from the manufacturer to the patient. Unlike other products however, drug prices do not always go up each time they change hands and they do not often reflect what is actually paid for the drug. As illustrated in the Congressional Budget Office graphic below, the pharmaceutical industry involves several buyers, sellers and payers (e.g., wholesaler, distributor, PBM pharmacy, insurer, provider, patient, etc.) and many different pricing schemes including:

- direct retail price (DIRP)

- wholesale acquisition cost (WAC)

- average sale price (ASP)

- average manufacturer price (AMP)

- actual acquisition cost (AAC)

- usual and customary (U\&C)

- maximum allowable cost (MAC)

- 340B public health service cost

- CMS federal upper limit (FUL)

- average wholesale price (AWP)

There is great complexity, and little in the way of logic, behind many of these price schemes, unfortunately.

Moreover, several other factors can impact the ultimate cost paid by consumers and payers alike that include: patient / drug assistance programs (manufacturer coupons,

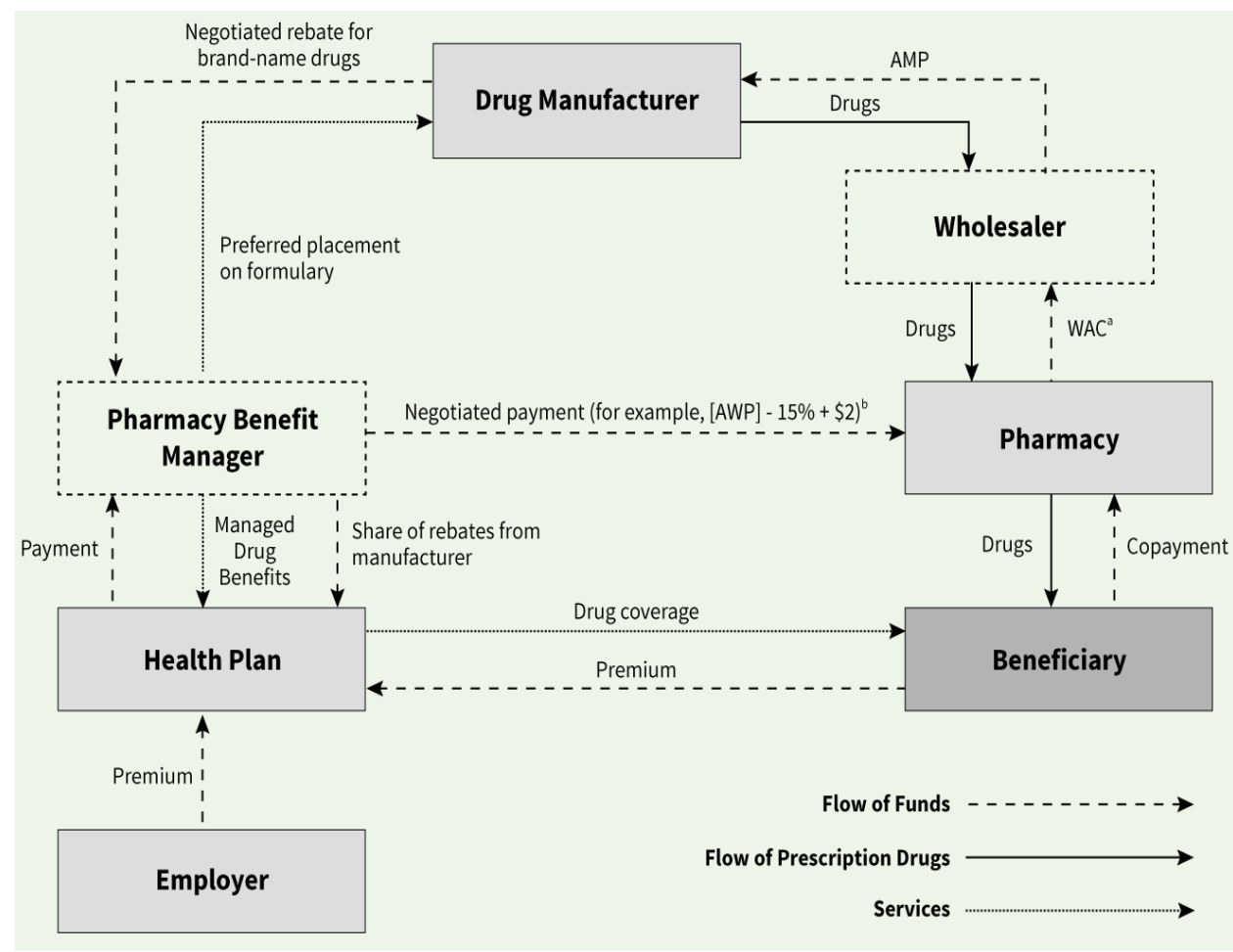
co-pay assistance), rebate and financial incentives for formulary placement, and fees (access, market share, administrative, data and service) that can add up toas much as $20 \%$ of AWP. All of this makes it difficult to speak precisely about drug costs.

AWP is the pricing benchmark used by the PBMs that administer pharmacy benefits. It is discounted based on a payer's size, Rx spend, formulary placement, etc. As such, it was used as the price basis for this analysis. For this study, drug pricing was based on AWP -15\% for the most cost-efficient available drug packaging option, as per data published by Alchemy Health Care Solutions, a CMS-recognized pricing source (as of February 2, 2022). 